\title{
On the Mechanism of the Froehde Reaction
}

\author{
Francisco Sánchez-Viesca*, Reina Gómez \\ Organic Chemistry Department, Faculty of Chemistry, National Autonomous University of Mexico, Mexico City (CDMX), Mexico \\ *Corresponding author: franviesca@yahoo.com
}

Received November 19, 2018; Revised December 24, 2018; Accepted January 16, 2019

\begin{abstract}
Although the Froehde reaction is widely used for alkaloid preliminary identification, there is no reaction mechanism in order to explain the reaction course and the end products. We found there can be two redox steps and we provide a reaction mechanism for both of them and give two routes for the second reaction. The chemical deportment of the reagent, molybdic acid and its derivatives is also discussed.
\end{abstract}

Keywords: alkaloids, aromatic hydroxylation, molybdene dioxide, molybdic acid, reactive intermediates, redox reactions

Cite This Article: Francisco Sánchez-Viesca, and Reina Gómez, "On the Mechanism of the Froehde Reaction.” World Journal of Organic Chemistry, vol. 7, no. 1 (2019): 1-4. doi: 10.12691/wjoc-7-1-1.

\section{Introduction}

Continuing our studies on organic reaction mechanisms [1-5], we turned our attention to the Froehde reaction [6] because the reactivity involved in this widely used colour test has not been cleared up.

We provide a complete reaction mechanism covering each stage of two redox reactions. This is interesting since it includes the organic chemistry related to the substrate, especially alkaloids, as well as the chemical deportment of the inorganic reagent, molybdic acid.

\section{Antecedents}

We present pertinent information on molybdenum, molybdic acid and its reduction derivatives. This will sustain the reaction mechanisms given in the next section.

The Froehde reagent, prepared from molybdic acid or sodium molybdate dissolved in hot sulphuric acid, is reduced by phenols and diverse alkaloids. Its principal use is for the preliminary identification of opioids.

The United States Department of Justice prepares the reagent by the addition of $100 \mathrm{ml}$ of hot concentrated sulphuric acid to $0.5 \mathrm{~g}$ of sodium molybdate or molybdic acid [7]. The Virginia State uses $0.5 \mathrm{~g}$ of ammonium molybdate in equal conditions.

Molybdene is in the Periodic Table d block, the transition elements, and in group VI A, the chromium group. There are three transition series, the first corresponding to the filling of the $3 \mathrm{~d}$ orbitals.

Molybdenum $(Z=42)$ is in the second series, this commences with yttrium $(\mathrm{Z}=39)$. Molybdene electronic structure is: Kr core, $4 d^{5}, 5 s^{1}$. Electron transfer from the $5 \mathrm{~s}$ to the $4 d$ orbitals may be noted in niobium $(Z=41)$, molybdenum $(\mathrm{Z}=42)$ and other atoms [8].
The structure of molybdic acid, dihydroxydioxomolybdenum [9], is in Figure 1. It has a hydrogen bond donor count 2, and since there are five d orbitals, it has an acceptor count 4 . These electrons plus the six covalent ones makes ten electrons in five d orbitals.<smiles>[H][R4](=O)O[Na]</smiles>

Figure 1. Molybdic acid structure

Molybdic acid forms yellow crystals of the monohydrate, $\mathrm{H}_{2} \mathrm{MoO}_{4} \cdot \mathrm{H}_{2} \mathrm{O}$. Gentle heating affords white needles of the anhydrous acid, [10].

An intense blue is produced by mild reduction. The products, known as molybdenum blue are oxides in which the oxidation state of the metal appears to be between +5 and +6 , [11]. Bruni gives the composition $\mathrm{Mo}_{2} \mathrm{O}_{5}, \mathrm{MoO}_{3}$.

The formation of dimolybdenum pentoxide is treated in the Discussion. The colour of the pentoxide is red-violet or dark violet.

Molybdic trioxide (molybdic anhydride) is light yellow and molybdene dioxide is red-violet [12]. This molybdene(IV) oxide is produced by reduction of the reagent after oxidation of organic substrates, as we will see in the next section.

Reaction between molybdic acid and sulphuric acid yields molybdenyl sulphate, $\mathrm{MoO}_{2} \mathrm{SO}_{4}$. It crystallizes out in brilliant, colourless, deliquescent prisms. This compound has been misnamed as molybdenum dioxysulphate [13]. The two oxygen atoms are in the oxycationic group $\mathrm{MoO}_{2}{ }^{2+}$, not in the anion. This compound, if formed in the Froehde reagent, does not intervene since it is not an oxidant.

Finally, there are lists of compounds that give a colour in the Froehde test, $[7,14]$. 


\section{Discussion}

There is a redox reaction in the Froehde test. However, no mechanism has been advanced. The molybdic salt does not react as such since the cation can be sodium or ammonium. Besides, molybdic acid can be used instead of the salts. Thus we provide a mechanism with this acid.

In the original work, Froehde employed the reagent only with morphine [15]. Since the electrodoting group [16] is the phenol we will use an abbreviated form instead of the complete morphine structure, Figure 2.

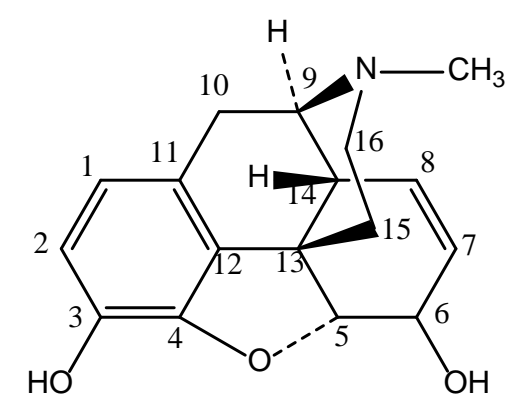

Figure 2. Morphine molecule with a chair structure

The first redox reaction is in Figure 3.

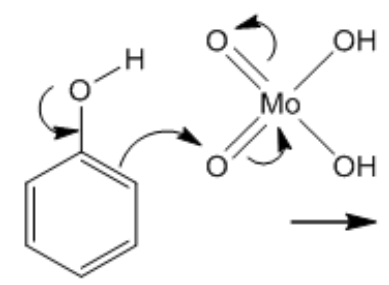

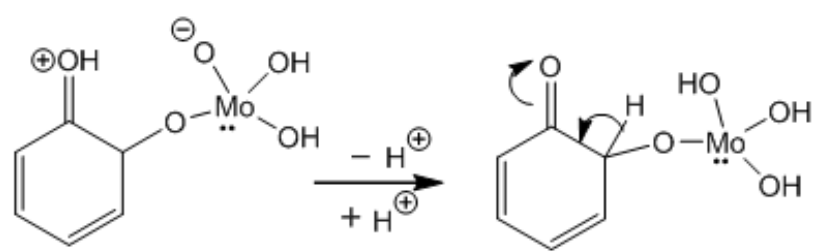

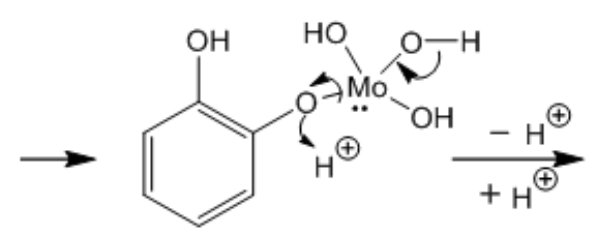<smiles>CC(C)(CO)[W](=O)O</smiles>

Figure 3. Mechanism of aromatic hydroxylation

The transient electronegative molybdenum atom is neutralized by polarization of the remaining double bonded oxygen atom. Electric charges are eliminated by proton transfer, and aromatization is achieved by keto-enol tautomerism. Protolysis of the organometallic intermediate affords a pyrocatechol structure and molybdene dioxide hydrate. The dioxide is coloured violet. This compound is sparingly soluble in sulphuric acid [17].
Molybdenum(IV) oxide is by itself sufficient to give the blue violet colour observed in the morphine chemical assay, although other compounds are also formed.

The two electrons accepted by the molybdenum atom are located in one of the empty d orbitals (see previous section).

Molybdenum dioxide can react with molybdic trioxide to give the dark violet dimolybdene pentoxide, Figure 4.

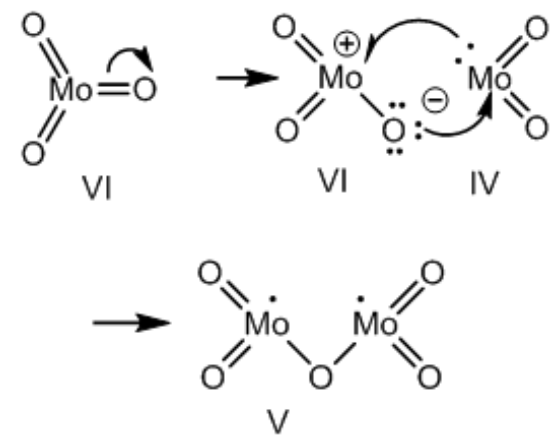

Figure 4. Formation of molybdene pentoxide

Other compound formed is $\mathrm{Mo}_{3} \mathrm{O}_{8}$, molybdene blue.

Pesez and Poirier [6] give the composition $\left(\mathrm{MoO}_{2}\right)_{2}$ $\left(\mathrm{MoO}_{4}\right)$ for this compound. This can be rationalized as follows: molybdenyl molybdate is formed by elimination of two water molecules between two molybdic acid molecules,

$$
\begin{aligned}
& \mathrm{O}_{2} \mathrm{Mo}(\mathrm{OH})_{2}+\mathrm{H}_{2} \mathrm{MoO}_{4} \\
& \rightarrow \mathrm{MoO}_{2}{ }^{++}+\mathrm{MoO}_{4}{ }^{--}+2 \mathrm{H}_{2} \mathrm{O} .
\end{aligned}
$$

Then transfer of one electron from a neutral molecule of molybdene dioxide to the above oxycation, gives two cation radicals $\mathrm{MoO}_{2}^{+}$.

This is in accordance with the presence of molybdenum (VI) in tha anion and molybdenum(V) in the two cation radicals. Thus, reduced molybdene(IV) oxide reacts with a molybdene(VI) species $\left(\mathrm{MoO}_{2}{ }^{++}\right)$to give two cations with an intermediate oxidation state, $\mathrm{V}$. Thus $\mathrm{Mo}_{3} \mathrm{O}_{8}$ is not an oxide, but a salt.

Bruni [10] gives the composition $\mathrm{Mo}_{2} \mathrm{O}_{5}, \mathrm{MoO}_{3}$ for molybdene blue, but this cannot be rationalized.

The reaction mechanism of further oxidation to the ortho quinone is given in Figure 5.

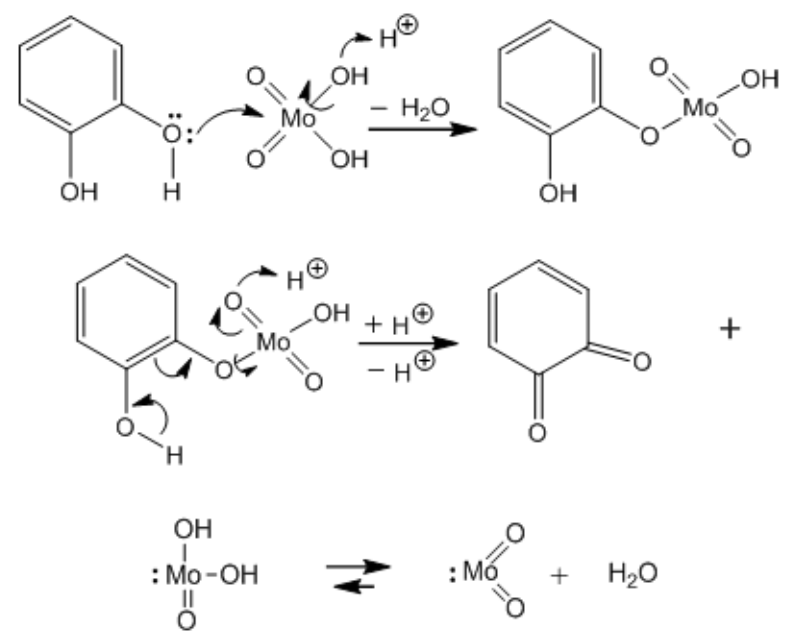

Figure 5. Second oxidation-reduction step 
An acid catalyzed esterification is followed by a redox reaction promoted by protolysis. A yellow ortho quinone is obtained plus hydrated molybdene dioxide. This mixture is green due to the blue/yellow combination.

There is a second route to the ortho quinone. A cyclic diester can be formed due to the presence of neighbouring groups. Protolysis of the organometallic intermediate yields the quinone and molybdene(IV) oxide, Figure 6.<smiles>O=S(=O)(O)Oc1ccccc1O[W](=O)(=O)O[W](=O)(O)O</smiles>

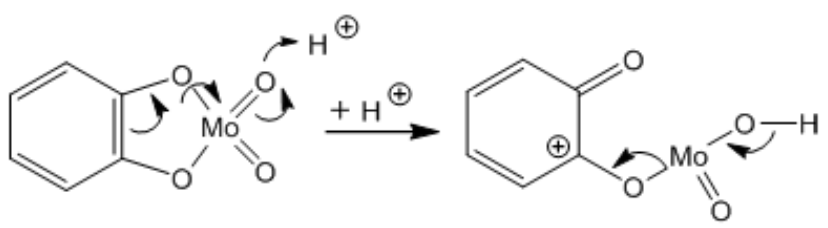<smiles>CC(C)C1CCC=CC1=O</smiles>

Figure 6. Ortho quinone formation via cyclic ester

The case of semisynthetic opioids is interesting: hydro-morphone hydrochloride, an agonist opioid with a keto group at C-6 and hydrogenated at the 7-8 positions, Figure 7 , behaves in a similar manner as morphine, giving a blue colour that turns purple.

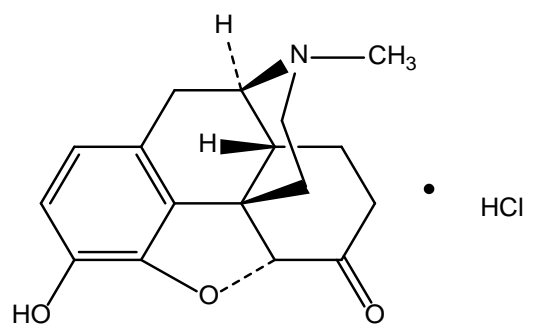

Figure 7. Hydromorphone hydrochloride

Now let us consider the nonphenolic opioids. Heroin hydrochloride, diacetylmorphine hydrochloride, gives a purple colour. This can be explained by transacetylation, releasing the free phenol group.

The opioids with a methoxy group at C-3 like codeine (methyl morphine) and codeine analogs such as hydrocodone (dihydrocodeinone) and oxycodone (with an additional hydroxy group), are cough suppressants, Figure 8, Figure 9, Figure 10.

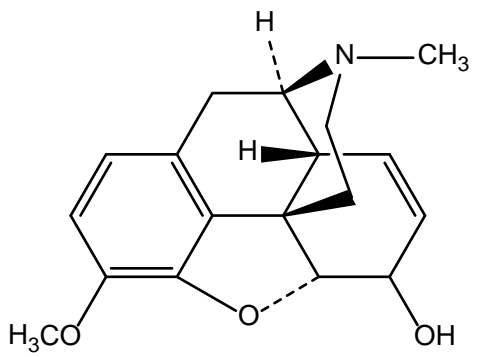

Figure 8. Codeine

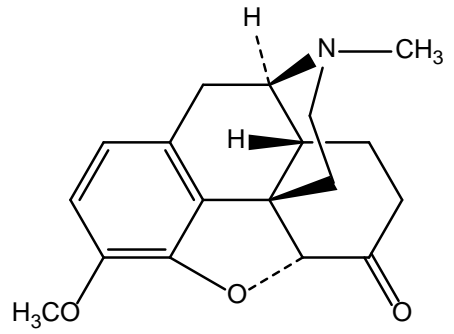

Figure 9. Hydrocodone

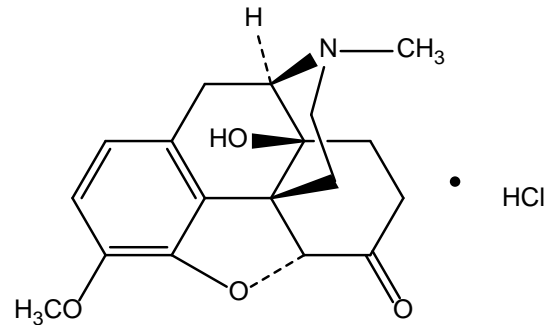

Figure 10. Oxycodone hydrochloride

These compounds cannot form easily a phenol group and present the same reactivity as morphine, hydromorphone or heroin. It would be necessary a Zeisel reaction with $\mathrm{HI} / \mathrm{AcOH}$ and heat at $120-130^{\circ}$ in an oil bath in order to demethylate the methoxy group, [18,19]. That this does not happen in the Froehde reaction conditions is in agreement with the very different colours observed: green, yellow, strong yellow, respectively.

Other interesting compound is mescaline, the naturally occurring psychedelic alkaloid. It is 3,4,5-trimethoxyphenethylamine, Figure 11.<smiles>COc1cc(CCN)cc(OC)c1OC</smiles>

Figure 11. Mescaline

It gives light yellow or yellow green in the Froehde test.This colour is in agreement with the codeine analogs results.

It is well known that many colour reactions are developed in concentrated mineral acid such as sulphuric acid and disappear on aqueous dilution (halochromism), [20,21].

So, it is probable that compounds that develop a colour with the Froehde reagent are simple halochromic compounds (coloured salts) and that there is not a redox reaction with them. It will be very interesting that staff with access to restricted drugs do the tests with just sulphuric acid and compare them with a supposed Froehde reaction. We have many positive colour tests with sulphuric acid and varied substrates.

\section{Conclusions}

Froehde tested morphine with a solution of sodium molybdate in sulphuric acid. We gave the pertinent 
information related to molybdic acid and its reduced derivatives in order to understand the ongoing mechanism in the Froehde reaction.

The phenolic compound reduces the formed molybdic acid, giving the blue colour of the reduced molybdene derivatives obtained: molybdene(IV) oxide (drab brownviolet, red-violet), molybdene(V) oxide (red.violet) and molybdene blue, $\mathrm{Mo}_{3} \mathrm{O}_{8}$, to which the compositions $\mathrm{Mo}_{2} \mathrm{O}_{5}, \mathrm{MoO}_{3}$ and $\left(\mathrm{MoO}_{2}\right)_{2}\left(\mathrm{MoO}_{4}\right)$ have been given.

We clarified which composition of this compound is correct and gave its formation sequence. This blue compound is not an oxide but a salt: molybdenyl(V) molybdate.

We have provided the reaction mechanism of a redox reaction that yields a pyrocatechol derivative and the above mentioned oxides.

A second oxidation step in the Froehde reaction has been also treated and two alternate routes were provided, depending if a simple esterification occurs or a cyclic ester is formed previously to the redox reaction.

The case of the nonphenolic opioids has also been discussed.

\section{References}

[1] Sánchez-Viesca, F. and Gómez, R., "On the mechanism of indirubin formation in the Baeyer- Emmerling synthesis”, Am. J. Chem., 8(4), 85-89, 2018.

[2] Sánchez-Viesca, F., Berros, M. and Gómez, R., “A complete and sustained Clemmensen reduction mechanism”, Am. J. Chem., 8(1), 8-12, 2018.

[3] Sánchez-Viesca, F. and Gómez, R., "Reactivities involved in the Seliwanoff reaction”, Modern Chemistry, 6(1), 1-5, 2018.
[4] Sánchez-Viesca, F., Berros, M. and Gómez, R., "On the mechanism of the Baeyer-Drewsen synthesis of indigo”, Am. J. Chem., 6(1), 18-22, 2016.

[5] Sánchez-Viesca, F. and Gómez, R., "On the regiochemistry in the Heyns rearrangement”, Am. J. Chem., 5(3), 86-89, 2015.

[6] Pesez, M. and Poirier, P., Méthodes et réactions de l'analyse organique, Masson, Paris, 1954, vol. 3, 9.

[7] Froehde reagent, https://www.revolvy.com/page/Froehde-reagent accessed: December 29, 2018.

[8] Brown, D. A., Comparative inorganic chemistry, McGraw-Hill, London, 1967, 23.

[9] Molybdic acid, PubChem Open Chemistry Data Base, CID 82208 accessed: December 29, 2018.

[10] Bruni, G., Química inorganica, 12a. ed., UTEHA, México, 1964, 367.

[11] Duffy, J. A., General inorganic chemistry, Longmans, London, 1966, 224-225.

[12] Bruylants, A., Jungers, J. C., Verhulst, J., Química general, vol. 2, Química mineral, Teide, Barcelona, 1965, 261.

[13] Remy, H., Treatise on inorganic chemistry, Elsevier, Amsterdam, 1963, vol. 2, 170.

[14] Froehde reagent, https://en.wikipedia.org/wiki/Froehde_reagent Accessed: December 29, 2018.

[15] A. Froehde, "Sur la recherche de la morphine”, Bull. Soc. Chim. Paris, 8(1), 166, 1867. (Gallica, BnF).

[16] Luder, W. F. and Zuffanti, S., The electronic theory of acids and bases, $2^{\text {nd }}$. ed., Dover, New York, 1961, 71-72.

[17] The molybdenum(IV) oxide, datasheets.scbt.com/sc-235882.pdf. Accessed: December 29, 2018.

[18] Shriner, R. L., Fuson, R. C. and Curtin, D. Y., The systematic identification of organic compounds, $4^{\text {th }}$. ed., J. Wiley, New York, 1958, 116-117.

[19] Wild, F., Characterization of organic compounds, $2^{\text {nd }}$ ed. Cambridge University Press, Cambridge, 1960, 102-103.

[20] Pesez, M. and Poirier, P., Méthodes et réactions de l'analyse organique, Masson, Paris, 1954, vol. 3, 227.

[21] Miall, S. and Mackenzie Miall, L., Diccionario de química, 2ª ed., Ed. Atlante, México, 1953, 515.

C The Author(s) 2019. This article is an open access article distributed under the terms and conditions of the Creative Commons Attribution (CC BY) license (http://creativecommons.org/licenses/by/4.0/). 